\title{
Study of redox mechanism of poly(o-aminophenol) using in situ techniques: evidence of two redox processes
}

\author{
H.J. Salavagione b, J. Arias-Pardilla a, J.M. Pérez a, J.L. Vázquez a, E. Morallón ${ }^{\text {a,* }}$, \\ M.C. Miras ${ }^{b}$, C. Barbero ${ }^{b}$ \\ ${ }^{a}$ Departamento de Química Física e Instituto Universitario de Materiales, Universidad de Alicante, Apartado 99,03080 Alicante, Spain \\ ${ }^{\mathrm{b}}$ Departamento de Química, Universidad Nacional de Río Cuarto, Agencia postal 3, Spain \\ Received 15 June 2004; received in revised form 5 October 2004; accepted 6 October 2004
}

The poly (o-aminophenol) (POAP) redox process has been studied in aqueous acid solution using spectroscopic and optic in situ techniques. The redox transition of the POAP from its completely oxidized state to its completely reduced state occurs through two consecutive reactions in which a charged intermediate species takes part. UV-Vis and Raman signals agree with an increase of the concentration of an intermediate species until the potential of the maximum redox peak, which later diminishes with the potential. oxidation, the polymer incorporates anions in a first process and thenexpels protons in a second one.

17 (C) 2004 Published by Elsevier B.V.

18 Keywords: Poly(o-aminophenol); In situ Raman spectroscopy; Probe beam deflection

\section{Introduction}

Since the discovery of conducting polymers there have been many studies dealing with the synthesis, characterization and properties of these polymers [1-5]. Polyaniline (PANI) and derivatives have been studied extensively, the electrochemical behavior being one of the more studied properties $[6,7]$.

On other hand, the polymerization of derivatives of aniline such as aminophenols is interesting since, unlike aniline [8] and other substituted anilines [9], they have two groups which could be oxidized. 0 -Aminophenol (OAP) is the only isomer that produces an electroactive polymer during its oxidation [10-14]. At the present time, it is agreed that poly(o-aminophenol) (POAP) is a ladder polymer formed by phenoxazine-type units. The voltammetric response of POAP is characteristic

\footnotetext{
* Corresponding author. Tel.: +34 965909590; fax: +34 965903537.
} E-mail address: morallon@ua.es (E. Morallón). of a reversible redox process with the presence of a broad peak during the positive scan and a narrower peak in the reverse scan. Generally, agreement exists in that the broad anodic peak corresponds to only one redox process.

Nevertheless, in similar redox polymers the broad peak has been assigned to two redox processes [15]. In addition, using in situ UV-Vis spectroscopy, the absorption of an intermediate species at $750 \mathrm{~nm}$ has been detected on POAP oxidation-reduction processes [16]. The appearance of this intermediate species cannot be explained by a single redox process. Furthermore, electron paramagnetic resonance (EPR) measurements of POAP on Pt electrodes in acidic medium suggested the existence of species of unpaired spin [17]. Komura et al. [18] proposed a probable redox reaction of the protonated polymer that consists of two redox steps. In both steps, the polymer exchanges both electrons and protons. 
Probe beam deflection (PBD) allows changes of the concentration profiles at the film|electrolyte interface during the electrochemical reaction to be recorded. PBD has contributed to the understanding of the ionic exchange in electroactive polymers such as polyaniline [19], poly $(N$-methylaniline) [20], polyaniline derivatives [21], polypyrrole [22], poly(1-naphtol) [23], poly(1hydroxiphenazine) [24] and poly(thiophene) [25].

In this paper we report a study of the redox mechanism of POAP using in situ techniques. Ionic exchange of the polymer was studied by PBD and the polymer was studied using in situ FTIR, UV-Vis and Raman spectroscopy. \\ 68 2. Experimental}

\section{2.1. Electrochemistry}

70 The $\mathrm{HClO}_{4}$ solutions were prepared from Merck 71 Suprapur concentrated acid. o-Aminophenol was from 72 Merck for synthesis and the water employed for the 73 preparation of the solutions was obtained from an Elga 74 Labwater Purelab Ultra system. $\mathrm{D}_{2} \mathrm{O}$ was from Aldrich 75 chemicals, $99.9 \%$ atom $\%$ D. A saturated calomel elec76 trode (SCE) immersed in the same solution was used 77 as the reference electrode.

78 Polymer films were obtained from a $5 \times 10^{-3} \mathrm{M}$ $79 o$-aminophenol solution in a supporting electrolyte of $801 \mathrm{M} \mathrm{HClO}_{4}$ by cycling the potential between -0.3 and $810.7 \mathrm{~V}$ at a scan rate of $50 \mathrm{mV} \mathrm{s}^{-1}$. In all cases, the elec82 trode covered with polymer was removed from the solu-

83 tion at $-0.1 \mathrm{~V}$ (reduced state). Then the modified 84 electrode was washed with water and was transferred 85 to a new cell for characterization by cyclic voltammetry, 86 in situ spectroscopy and PBD. The film thickness was in 87 all cases between 20 and $30 \mathrm{~nm}$, measured from the vol88 tammetric charge [11].

89 Several electrode materials were used (glassy carbon, 90 platinum and gold) and in all cases the same voltammet91 ric behavior of the POAP polymer was obtained.

\section{2.2. In situ FTIR spectroscopy}

93 A Nicolet Magna 850 spectrometer equipped with a 94 liquid nitrogen-cooled MCT detector was employed 95 for the in situ FTIR measurements. The sample com96 partment was purged throughout the experiment using 97 a 75-50 Balston clean air package. The electrode used 98 was a polycrystalline platinum disc $8 \mathrm{~mm}$ in diameter 99 obtained from Goodfellow Metals (purity 99.99\%). 100 The disc was mounted on a glass tube and its surface 101 was polished using alumina powder of several sizes (1, 1020.3 and $0.05 \mu \mathrm{m}$ ) before the thermal treatment [10]. A 103 platinum electrode was used as the counter-electrode. 104 The thin-layer spectroelectrochemical cell was made of glass and was provided with a prismatic $\mathrm{CaF}_{2}$ window beveled at $60^{\circ}$. Spectra were collected at $8 \mathrm{~cm}^{-1}$ resolution and are presented as $\Delta R / R$.

\subsection{In situ Raman spectroscopy}

Raman spectra were obtained with a LabRam spectrometer (from Jobin-Ivon Horiba). The system has an extremely high detecting sensibility and it uses a single spectrograph equipped with a notch filter in order to filter the Rayleigh scattering and holographic gratings $\left(1800\right.$ and 600 grooves $\left.\mathrm{mm}^{-1}\right)$. The slit and pinhole employed were 200 and $700 \mu \mathrm{m}$, respectively. The excitation line was provided by a $17 \mathrm{~mW} \mathrm{He}-\mathrm{Ne}$ laser at $632.8 \mathrm{~nm}$, and the laser power delivered at the sample was held at $4 \mathrm{~mW}$. The laser beam was focused through a $50 \times$ long-working objective $(0.5 \mathrm{NA})$. The diameter of the laser beam spot on the sample surface was $2 \mu \mathrm{m}$. The sample viewing system consisted of a color television camera attached to the microscope. The spectrometer resolution was better than $3 \mathrm{~cm}^{-1}$ and the detector was a Peltier cooled charge-coupled device (CCD) $(1064 \times 256$ pixels $)$. The time needed for the analysis (averaging included) was $27 \mathrm{~s}$.

The spectro-electrochemical cell used for the acquisition of Raman spectra was made in Teflon with the working electrode facing up as the LabRam spectrometer utilized a backscattering configuration to collect the Raman scattering through a confocal microscope vertically. The cell was designed with a silica window to form a closed system in order to prevent the etching of the lens and to eliminate any possible pollution of solution from the air. At the same time, the cell was capable of purging gas during the experiments or serving as a flow cell.

For in situ Raman spectroscopy measures a $\mathrm{Au}$ working electrode imbedded in a Teflon ${ }^{\circledR}$ rod was used.

\subsection{Probe beam deflection}

The electrochemical control of PBD experiments was performed using a potentiostat (AMEL 2049). The PBD arrangement was similar to the at described before [26]. The basic components of the PBD system were a $5 \mathrm{~mW}$ He-Ne laser (Melles Griot, 05 LHP11) and a bicell position-sensitive detector (UDT PIN SPOT /2D). The laser beam was focused by a $50 \mathrm{~mm}$ lens to a diameter of roughly $60 \mu \mathrm{m}$ in front of the planar electrode. The actual beam/electrode distance and diffusion coefficient were estimated by measuring chronodeflectometric pulses at different relative distances $(x)$ and using the relationship between the time of maximum signal and distance $\left(t_{\max }=x^{2} / 6 D\right)$ with the same electrode/electrolyte system [27]. An appropriate correction was made for the beam refraction at the air|medium interface using the refractive index of the medium measured with a
140 
157 refractometer. The electrochemical cell was a $2 \times 2 \mathrm{~cm}$ 158 optical glass cuvette with $2 \mathrm{~cm}$ of path length, which 159 was mounted on a 3 axis tilt table (Newport). The work160 ing electrodes were $3 \mathrm{~mm}$ thick glassy carbon plates $161(1 \times 3 \mathrm{~cm})$ with non active areas covered with a layer 162 of epoxy and the active area polished with alumina pow163 der (down to $1 \mu \mathrm{m}$ ). The exposed area was of $0.5 \mathrm{~cm}^{2}$.

164 The counter electrode was a coiled Pt wire and the refer165 ence electrode was a conventional SCE connected with 166 the cell by a plastic tube. The counter electrode and ref167 erence connecting tube were situated facing the working 168 electrode outside the path of the beam. A micrometric 169 translation stage allowed for controlled positioning of 170 the sample with respect to the laser beam in $10 \mu \mathrm{m}$ steps.

171 The position sensitive detector was placed $25 \mathrm{~cm}$ behind

172 the electrochemical cell and had a sensitivity of $3 \mathrm{mV} /$

$173 \mu \mathrm{m}$, which resulted in a deflection sensitivity of 1

$174 \mathrm{mrad} / \mathrm{V}$. The deflection signal was processed using a

175 position monitor (UDT 201 DIV). The signal of the

176 two photodiodes making the bicell detector were sub-

177 tracted and normalized to the overall signal in order

178 to minimize the effect of laser intensity fluctuations.

179 All parts of the system were mounted on an optical rail,

180 resting on a stable optical bench.

181 When positive charges are created in a polymeric film

182 (oxidation), this means that either anions are inserted or

183 cations are expelled to maintain the electroneutrality. If

184 the first occurs, a positive deflection due to a decrease of

185 ion concentration in the solution near the electrode is

186 observed. If cations are expelled, a negative deflection

187 caused by an increase of ion concentration in the solu-

188 tion is produced. During reduction, the opposite is true.

189 The PBD signal is affected by a diffusional delay be-

190 cause the probe beam travels at a certain distance away

191 from the electrode surface. Such a delay could compli-

192 cate the interpretation of PBD data. One way to elimi-

193 nate the delay has been proposed by Vieil and Lopez

194 [28] and involves the temporal convolution of the cur-

195 rent response with a mass transfer function. The expres-

196 sion of the PBD signal is

197

$$
\theta(x, t)=\left(\frac{l_{\mathrm{e}}}{n} \frac{\partial n}{\partial c}\right)\left(\frac{1}{D_{\mathrm{MA}}}\right)\left[\left(\frac{x}{2 \sqrt{\left(\pi D_{\mathrm{MA}} t^{3}\right)}} \mathrm{e}^{-x^{2} / 4 D_{\mathrm{MA}} t}\right) * I(t)\right]
$$

200 201 were processed using a convolution script in Matlab 5.1 (MathWorks). ${ }^{1}$

\section{Results and discussion}

Fig. 1 shows the voltammograms of POAP obtained on a glassy carbon electrode at different concentrations of $\mathrm{HClO}_{4}$ solution. At $1 \mathrm{M} \mathrm{HClO}_{4}$ the typical behavior of POAP is observed (Fig. 1, dashed line), i.e., a broad anodic peak at $0.11 \mathrm{~V}$ with its corresponding cathodic counterpart at $0.09 \mathrm{~V}$. The same voltammetric profile is obtained with different electrode materials $(\mathrm{Pt}, \mathrm{Au}$, etc.) $[11,29,30]$. The redox response of poly ( $o$-aminophenol) is usually due to the oxidation-reduction of phenoxazine units in the polymer $[29,31]$. There is little spectroscopic support for the structure of the POAP. Moreover, the agreement of redox potential and spectroscopic data between 2-aminophenoxazin-3-one (3APZ) and the polymer suggests that the main chain contains phenoxazine unit $[10,32]$.

Fig. 1 shows the voltammograms for different perchloric acid concentrations, in which it is possible to observe that both the oxidation and reduction peak separate in to two peaks as the acid concentration increases. At $5 \mathrm{M} \mathrm{HClO}_{4}$ two processes are clearly observed, i.e., a peak at $0.18 \mathrm{~V}$ and a shoulder at $0.37 \mathrm{~V}$ during the positive scan. These two processes appear as two very small peaks during the negative scan. As can be seen, the peak corresponding to the first redox process also shifts with the $\mathrm{HClO}_{4}$ concentration. This behavior should be due to the fact that the variation of the electrolyte concentration implies changes in both proton and perchlorate concentration. However, both peaks are affected in a different manner and therefore it is possible to recognize the existence of two redox processes.

The use of spectroscopic techniques coupled to electrochemical systems allows the identification of structural changes in the polymer during redox processes. Fig. 2 shows the Raman spectra of POAP films on an Au electrode at different applied potentials. In Table 1 are listed the bands obtained for a POAP in situ Raman spectrum acquired at $0.1 \mathrm{~V}$ and the assignation of this band. Bands at 1593, 1474, 1390 and $1160 \mathrm{~cm}^{-1}$ are associated with quinoid groups [33-35], while the bands at 1520 and $576 \mathrm{~cm}^{-1}$ are associated with aromatic rings [34]. The band at $1328 \mathrm{~cm}^{-1}$ has been attributed to radical semiquinone $-\mathrm{C}-\mathrm{N}^{+}$- - stretching in the emeraldine salt state in polyaniline $[35,36]$. The band at $1638 \mathrm{~cm}^{-1}$ has been assigned to $-\mathrm{C}=\mathrm{N}-$ in quinonimine units $[33,34]$. The intensity of some of these bands depends on the potential applied to the polymer film. The behavior of

\footnotetext{
I The MatLab script is available from one of the authors (cbarbero@exa.unrc.edu.ar) upon request.
} 


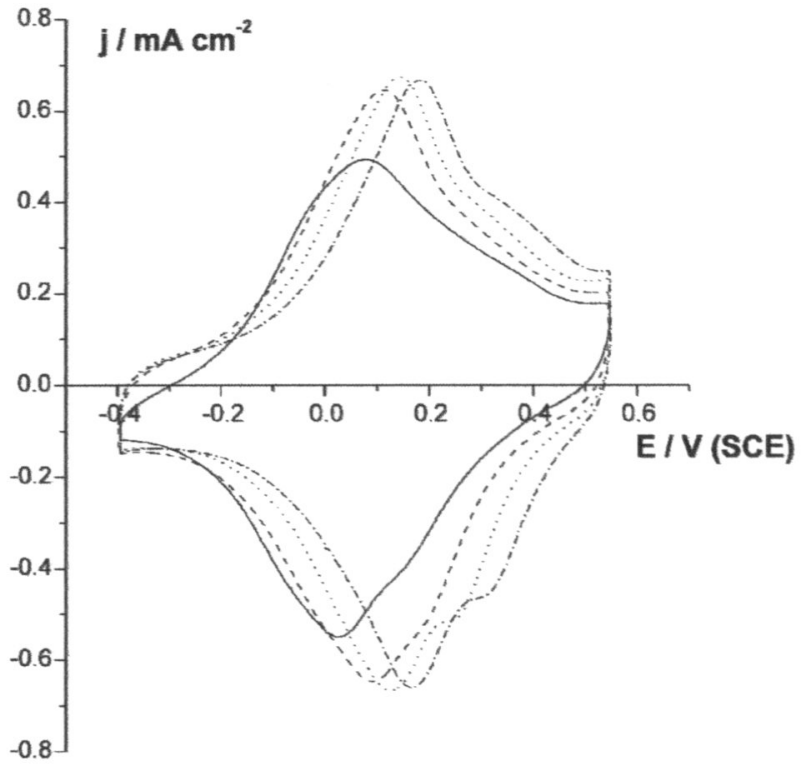

Fig. 1. Cyclic voltammograms of POAP-modified glassy carbon electrodes in $0.1 \mathrm{M}(-), 1 \mathrm{M}(-\ldots), 3 \mathrm{M}(\ldots)$ and $5 \mathrm{M}(\ldots \ldots)$ $\mathrm{HClO}_{4}$ electrolyte solution. Scan rate $=50 \mathrm{mV} \mathrm{s}^{-1}$.

Table 1

Vibration modes observed by Raman spectroscopy in POAP-modified $\mathrm{Au}$ electrodes at $0.1 \mathrm{~V}$ in $1 \mathrm{M} \mathrm{HClO}_{4}$ solution

\begin{tabular}{ll}
\hline Wavenumber $\left(\mathrm{cm}^{-1}\right)$ & Vibration modes \\
\hline 1638 & $-\mathrm{C}=\mathrm{N}-$ stretching of quinonimine units \\
1593 & $-\mathrm{C}=\mathrm{C}^{-}$stretching of quinoid units or \\
& $\mathrm{N}-\mathrm{H}^{+}$deformation vibration on \\
& secondary amines \\
1520 & $-\mathrm{C}=\mathrm{C}-$ stretching in the aromatic ring \\
1474 & $-\mathrm{C}=\mathrm{N}-$ stretching of quinoid units \\
1390 & $\mathrm{C}-\mathrm{C}$ stretching of quinoid units \\
1328 & $-\mathrm{C}-\mathrm{N}^{+}-$stretching \\
1160 & $\mathrm{C}-\mathrm{H}$ bending in-plane \\
925 & Perclorate vibration band \\
576 & Ring deformation of benzenoid units \\
\hline
\end{tabular}

261 the bands with the potential indicates that, when the 262 potential increases, the band at $1474 \mathrm{~cm}^{-1}$ increases 263 and the band at $1638 \mathrm{~cm}^{-1}$ also increases until a poten264 tial of ca. $0.2 \mathrm{~V}$ and there after it diminishes. The in265 crease of the band at $1474 \mathrm{~cm}^{-1}$, attributed to $-\mathrm{C}=\mathrm{N}$ -

266 stretching, indicates the increase of quinoid units in 267 the polymer. The fitting of the bands in Fig. 2 by Lor268 entz curves allows one to quantify the evolution with 269 the potential of the species related to the 1474 and $2701638 \mathrm{~cm}^{-1}$ bands. Due to this, the evolution of the inte271 grated Raman intensities have been obtained referring 272 the areas of these bands to the area of that correspond273 ing to the symmetrical stretching of the perchlorate an274 ion [34], at $925 \mathrm{~cm}^{-1}$, which does not change 275 significantly with the potential (internal standard). De276 spite the fact that the perchlorate anions can enter or

277 leave the polymer film during the redox processes, the

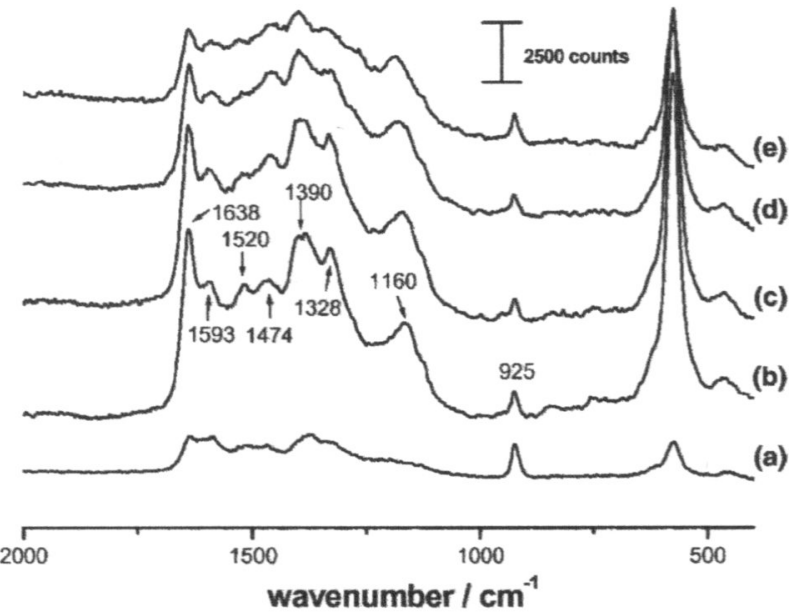

Fig. 2. Surface Raman spectra of a POAP-modified Au electrode in $\mathrm{M} \mathrm{HClO}_{4}$ solution at (a) $-0.1 \mathrm{~V}$, (b) $0.1 \mathrm{~V}$, (c) $0.2 \mathrm{~V}$, (d) 0.3 and (e) 0.5 $\mathrm{V}$ electrode potential.

variation of the Raman band at $925 \mathrm{~cm}^{-1}$ is negligible considering the concentration of these anions in the solution.

Fig. 3 shows the evolution of the integrated Raman intensities for both the 1474 and $1638 \mathrm{~cm}^{-1}$ bands with potential. It can be seen that the integrated intensity of the band at $1638 \mathrm{~cm}^{-1}$, assigned to quinonimine units, increases until a potential around $0.15 \mathrm{~V}$ is obtained and then, decreases. However, the integrated intensity of the band at $1474 \mathrm{~cm}^{-1}$, assigned to quinoid units, increases until $0.15 \mathrm{~V}$ and then it is maintained. The integrated intensity could be related with the concentrations of species responsible for these bands. Thus, the behavior of the band at $1638 \mathrm{~cm}^{-1}$ corresponds to a typical intermediate species. The maximum is only $0.04 \mathrm{~V}$ above the peak potential $\left(E_{\mathrm{p}}=0.11 \mathrm{~V}\right)$ in Fig. 1. Since POAP

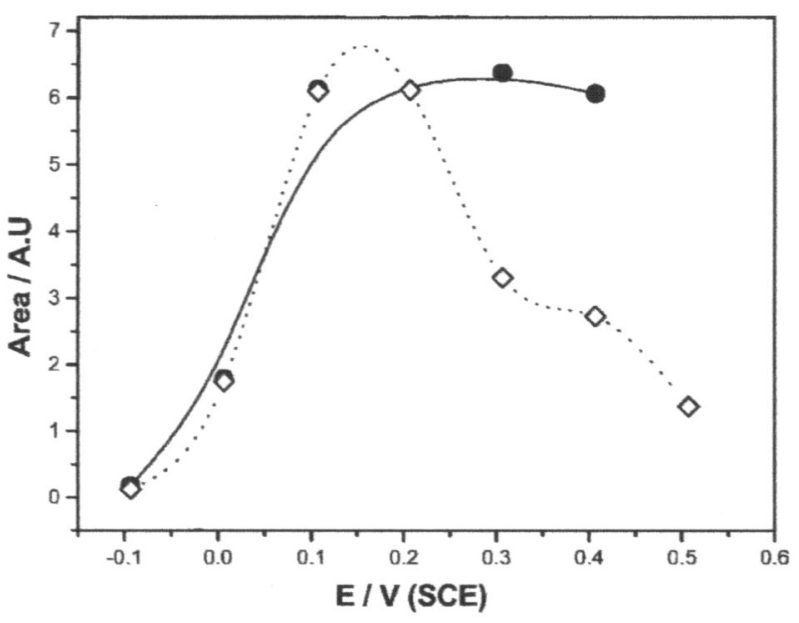

Fig. 3. Dependence of the relative area of $1474 \mathrm{~cm}^{-1}$ (full circle) and $1638 \mathrm{~cm}^{-1}$ (open square) Raman band on the electrode potential for a POAP-modified Au electrode in $1 \mathrm{M} \mathrm{HClO}_{4}$ solution. 
294 has a conductivity maximum at this $E_{\mathrm{p}}[16]$, the interme295 diate species could be related to the polymer conductiv296 ity and then, it could correspond to a charged species.

297 The existence of an intermediate species suggests that 298 the oxidation of POAP occurs through two consecutive 299 reactions from the totally reduced phenoxazine form to 300 the completely oxidized one, through a charged species, 301 which could be a cation radical. Tucceri et al. [16] ob302 served three electronic transitions at 340, 440 and 750 $303 \mathrm{~nm}$ in the in situ UV-Vis spectra (Fig. 4). Fig. 4 shows 304 the variation of the absorbances of the three peaks dur305 ing the oxidation of POAP. Assuming that the Lam306 bert-Beer law is applicable in this case because the 307 thickness of the polymer is very small, the absorbances 308 of the peaks at 340,440 and $750 \mathrm{~nm}$ are directly propor309 tional to the concentrations of the related species. The 310 authors attributed the band at $340 \mathrm{~nm}$ to the phenoxa311 zine structure, which correspond to the totally reduced 312 state of the polymer, which disappears with an increase 313 of the oxidation potential. On other hand, the band at $314440 \mathrm{~nm}$, attributed by the same authors to the oxidized 315 phenoxazine units, increases with the potential (Fig. 316 4). However, they did not find explanation for the band 317 at $750 \mathrm{~nm}$. This band was assigned in polyaniline to the 318 transition of the exciton of quinone and it is related to 319 the hopping electronic inter and intrachain [37,38]. Fur320 thermore, this band at $750 \mathrm{~nm}$ also depends on the oxi321 dation state of the polymer [39], displaying a similar behavior to the integrated Raman intensity of the band at $1638 \mathrm{~cm}^{-1}$ (Fig. 3). The maximum of absorbance of both bands $\left(750 \mathrm{~nm}\right.$ and $\left.1638 \mathrm{~cm}^{-1}\right)$ appear approximately at the same potential. These results support the existence of two redox processes in the oxidation of the POAP as in other redox polymers [15]. In addition, Raman and UV-Vis measurements suggest that the

third species could be a cation radical, in agreement with the results obtained by EPR [17].

In previous reports [10] we have compared in situ FTIR spectra of POAP and phenoxazine to try to clarify the structure of the POAP during the redox process. Fig. 5 shows the spectra, obtained for a $\mathrm{Pt}$ electrode in $\mathrm{D}_{2} \mathrm{O}+\mathrm{I} \mathrm{M} \mathrm{HClO}_{4}$ solution, taking the reference spectrum at $-0.14 \mathrm{~V}$ and stepping the sample potential to higher values. The reference spectrum contains vibrational information on the reduced polymer form and then the potential to which the sample is taken was increased to include vibrational information associated with the oxidized form of POAP. Fig. 5 displays one clear positive band at $1517 \mathrm{~cm}^{-1}$ when the sample potential increases to $0.16 \mathrm{~V}$. This band can be assigned to the $\mathrm{C}=\mathrm{C}$ stretching of the aromatic ring, which disappears upon polymer oxidation. The spectrum at $0.16 \mathrm{~V}$ also shows several negative bands at 1564, 1606 and 1648 $\mathrm{cm}^{-1}$ which are assigned to quinoid ring or $\mathrm{C}=\mathrm{N}$ stretching vibrations in the phenoxazine units produced during polymer oxidation. The intensities of these bands increase with the potential. The band at $1648 \mathrm{~cm}^{-1}$ could be assigned to $-\mathrm{C}=\mathrm{N}$ stretching, which, in conjugation with the phenyl group, shifts its frequency to higher values [40]. A negative band is also observed at $1330 \mathrm{~cm}^{-1}$ when the potential is stepped to $0.16 \mathrm{~V}$. This band could also be assigned to $\mathrm{C}=\mathrm{N}$ stretching of quinoid rings containing $\mathrm{C}=\mathrm{N}$ and $\mathrm{C}-\mathrm{N}$ groups, as has been done in the case of polyaniline [41].

Probe beam deflection is an optical in situ technique which allows one to record changes of the concentration profiles on the film/electrolyte interface during the electrochemical reaction. Therefore, PBD has been used

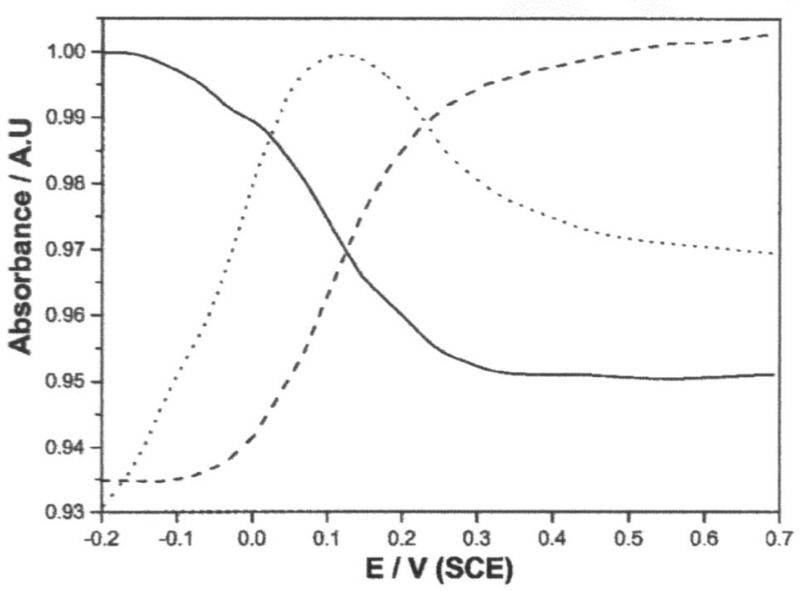

Fig. 4. Dependence of the absorbance at $340 \mathrm{~nm}$ (solid line), $440 \mathrm{~nm}$ (dashed line) and $750 \mathrm{~nm}$ (dotted line) on the electrode potential during POAP oxidation in $0.4 \mathrm{M} \mathrm{NaClO}_{4}+0.1 \mathrm{M} \mathrm{HClO}_{4}$ solution.

\section{$\Delta R / R=1 \%$}

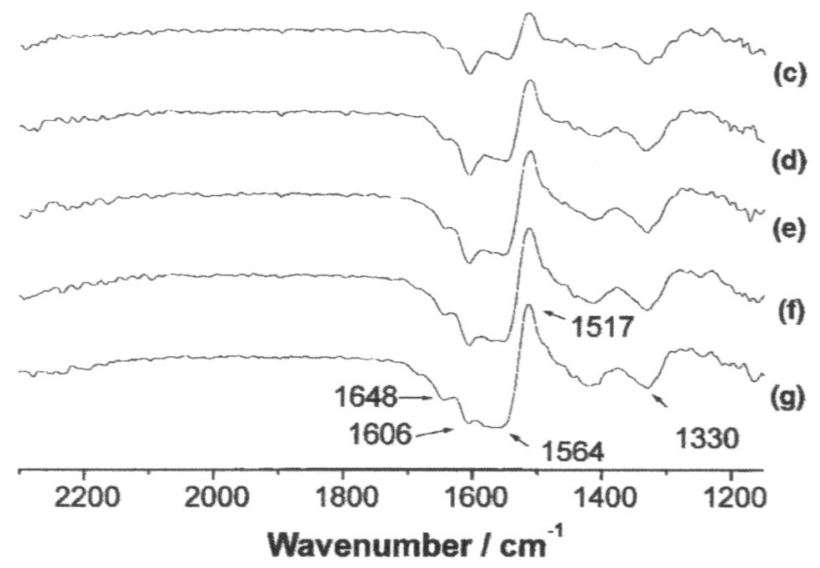

Fig. 5. In situ FTIR spectra of POAP-modified Pt electrode (100 interferograms) in $1 \mathrm{M} \mathrm{HClO}_{4}+\mathrm{D}_{2} \mathrm{O}$ solution at different sample potentials. (a) $-0.04 \mathrm{~V}$, (b) $0.06 \mathrm{~V}$, (c) $0.16 \mathrm{~V}$, (d) $0.26 \mathrm{~V}$, (e) $0.36 \mathrm{~V}$, (f) $0.46 \mathrm{~V}$ and $(\mathrm{g}) 0.66 \mathrm{~V}$. Reference potential $-0.14 \mathrm{~V}$. 
362 to determine the ionic exchange mechanism of POAP.

363 For this purpose, poly (o-aminophenol) was generated 364 in $1 \mathrm{M} \mathrm{HClO}_{4}$ solution using a glassy carbon flat elec-
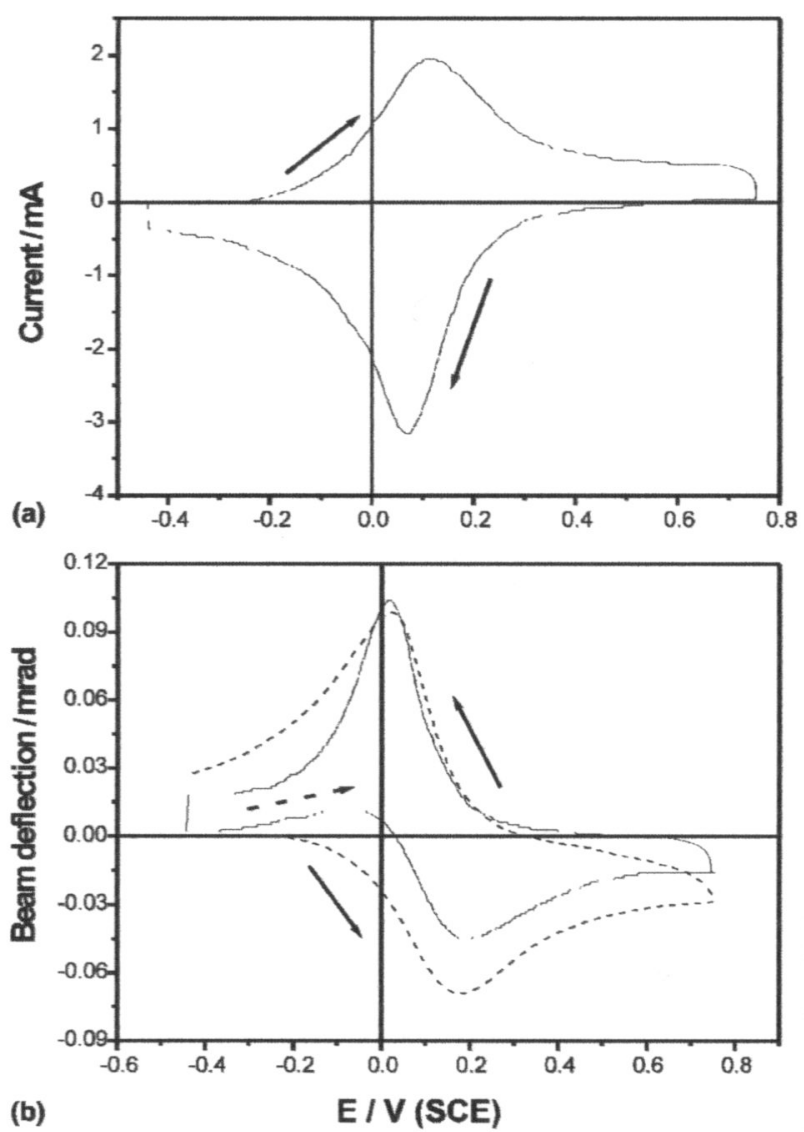

Fig. 6. Cyclic voltammogram (a) and deflectogram (b) of thin POAP films on glassy carbon electrodes in $1 \mathrm{M} \mathrm{HClO}_{4}$ electrolyte solution. Scan rate $=50 \mathrm{mV} / \mathrm{s}$. Distance beam/electrode $=75 \mu \mathrm{m}$. The dashed line in (b) is calculated by convolution of the current depicted in (a) with $D=3.3 \times 10^{-5} \mathrm{~cm}^{2} / \mathrm{s}, n=1.334$, and $\mathrm{d} n / \mathrm{d} c=6.8 \times 10^{-3} \mathrm{M}^{-1}[42]$. trode. After 180 cycles the modified electrode was washed with abundant water and transferred to the PBD cell. Fig. 6 shows both cyclic voltammograms (Fig. 6(a)) and deflectograms (Fig. 6(b)) recorded simultaneously for a POAP in $1 \mathrm{M} \mathrm{HClO}_{4}$ solution. During the oxidation scan, PBD signals show a positive deflection until a potential of $0.01 \mathrm{~V}$ is reached, followed by a negative stronger deflection. Positive deflection, in this case, corresponds to a decrease of perchlorate concentration in the solution near the electrode, indicating anion insertion in the film because positive charges are created in the POAP. Negative deflection corresponds to an increase of ion concentration in the solution near the electrode, indicating cation expulsion (in this case protons) from the POAP. On the other hand, during the reduction scan only a positive deflection is observed, which could corresponds to a simultaneous expulsion of $\mathrm{ClO}_{4}^{-}$and insertion of protons, the last process being dominant.

To check this, a PBD profile was simulated by convolution of the current response using parameters reported in the literature [42] and considering that only protons are exchanged between the solution and POAP (dashed line in Fig. 6(b)). As can be seen, the simulated profile fits reasonably well with the backward scan but differs significantly in the forward scan suggesting that not only protons but also perchlorate anioris are exchanged during the positive scan.

The information obtained by PBD supports the existence of an intermediate species suggested by Raman, UV-Vis and FTIR in situ spectroscopies. Therefore, Scheme 1 shows the proposed redox mechanism of POAP according to these new data. According to this mechanism, the first step involves mainly the anion exchange, whereas in the second step the insertion/expulsion of protons is produced. Therefore, it is clear that the $\mathrm{pH}$ of the solution affects the two redox processes in different ways.

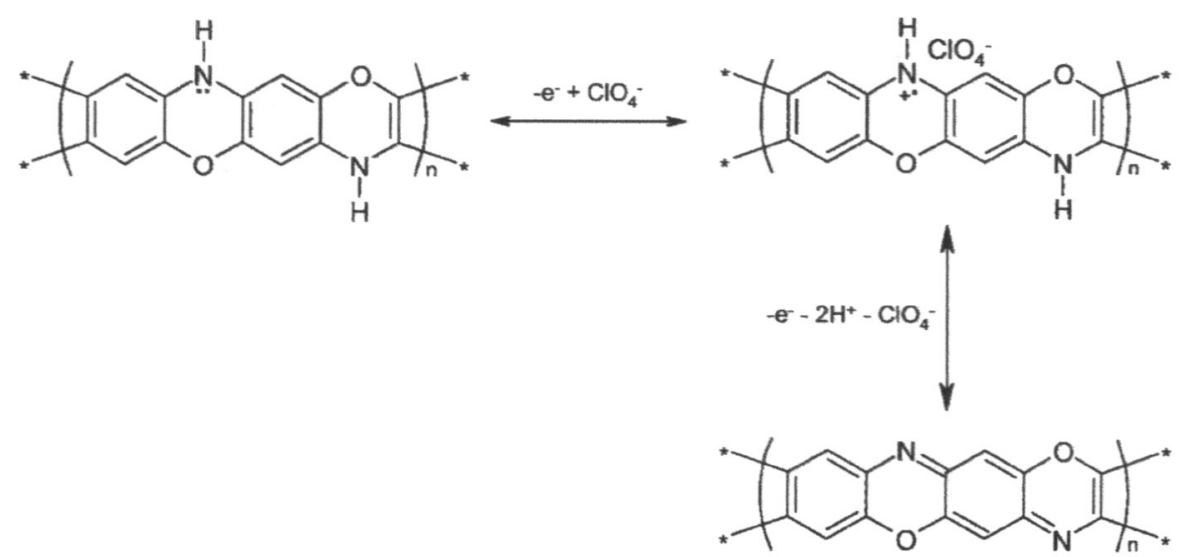

Scheme 1. Reaction scheme for the POAP oxidation in acidic medium. 


\section{Conclusions}

404

The ionic exchange mechanism of POAP films has

405 been analyzed in detail by means of spectroscopic and

406 optical in situ techniques like Raman and FTIR spec-

407 troscopies and PBD. From the data obtained, an im-

408 proved mechanism with respect to that previously

409 published has been proposed in the redox transition of

410 POAP. This mechanism involves a charged intermediate

411 when the polymeric film is changed from its reduced

412 state to its oxidized state.

413 The wide voltammetric peak that is obtained in $0.1 \mathrm{M}$

$414 \mathrm{HClO}_{4}$ solution for the POAP splits into two voltam-

415 metric peaks when the concentration of the perchloric

416 acid increases. This result indicates that there are two re-

417 dox processes. The PBD results support this fact and

418 suggest that during the oxidation of the POAP polymer,

419 the incorporation of anions at less positive potentials

420 and the expulsion of protons from the polymer at more

421 positive potentials are produced simultaneously.

422 Based on the data obtained from the in situ tech-

423 niques used in this work, a improved redox mechanism

424 of POAP is proposed ( Scheme 1).

\section{Acknowledgements}

Financial support by the Generalitat Valenciana (CTIAE/A/03/211) and Ministerio de Ciencia y Tecnología (MAT2001-1007) projects, as well as CONICET, SECYT-UNRC, Agencia Córdoba Ciencia and FONCYT (Argentina) are gratefully acknowledged. C. Barbero is a permanent research fellow of CONICET. H.J.S. thanks FONCYT for a graduate fellowship. Financing of the collaboration between Universidad de Alicante and UNRC by Fundación Antorchas is gratefully acknowledged.

\section{References}

[1] A.G. MacDiarmid, Angew. Chem. Int. Ed. 40 (2001) 2581 (references therein).

[2] G. Inzelt, M. Pineri, J.W. Schultze, M.A. Vorotyntsev, Electrochim. Acta 45 (2000) 2403 (references therein).

[3] A.G. MacDiarmid, L.S. Yang, W.S. Huang, B.D. Humphrey, Synth. Met. 18 (1987) 393.

[4] E.M. Genies, M. Lapkowski, P. Noel, S. Langlois, M.N. Collomb, F. Miquelino, Synth. Met. 43 (1991) 2847.

[5] J.M. Ginder, A.J. Epstein, A.G. MacDiarmid, Synth. Met. 37 (1990) 45.

6] L.H.C. Mattoso, A.G. MacDiarmid, in: J.C. Salamone (Ed.), Polymeric Materials Encyclopedia, vol. 7, CRC Press, Boca Raton, 1996, p. 5505.

[7] W.S. Huang, B.D. Humprey, A.G. MacDiarmid, J. Chem. Soc., Faraday Trans. 1182 (1986) 2385.

[8] H. Yang, A.J. Bard, J. Electroanal. Chem. 339 (1992) 423.
[9] N. Yamada, K. Teshima, N. Kobayashi, R. Hirohashi, J. 453 Electroanal. Chem. 394 (1995).

[10] H.J. Salavagione, J. Arias, P. Garcés, E. Morallón, C. Barbero, 455 J.L. Vázquez, J. Electroanal. Chem. 565 (2004) 375.

[11] C. Barbero, J. Zerbino, L. Sereno, D. Posadas, Electrochim. Acta 457 32 (1987) 693.

[12] A.Q. Zhang, C.Q. Qui, Y.Z. Chen, J.Y. Lee, J. Electroanal. Chem. 373 (1994) 115.

[13] D. Gonfçalves, R.C. Faria, M. Yonashiro, L.O.S. Bulhoes, J. Electroanal. Chem. 487 (2000) 90.

[14] R. Tucceri, J. Electroanal. Chem. 562 (2004) 173.

[15] O. Haas, Faraday Discuss. Chem. Soc. 88 (1989) 123.

[16] R.I. Tucceri, C. Barbero, J.J. Silber, L. Sereno, D. Posadas, Electrochim. Acta 42 (1997) 919.

[17] M. Ortega, Thin Solid Film 37 (2000) 2835

[18] T. Komura, Y. Ito, T. Yamaguti, K. Takahasi, Electrochim. Acta 43 (1998) 723

[19] C. Barbero, M.C. Miras, R. Kötz, O. Haas, J. Electrochem. Soc. 138 (1991) 669

[20] C. Barbero, M.C. Miras, R. Kötz, O. Haas, J. Electroanal. Chem. 310 (1991) 437

[21] H.J. Salavagione, D.F. Acevedo, M.C. Miras, C. Barbero, Port. Electrochim. Acta (2003) 939.

[22] V.M. Schmidt, C. Barbero, R. Kötz, J. Electroanal. Chem. 352 (1993) 301

[23] M.C. Pham, J. Moslih, C. Barbero, O. Haas, J. Electroanal. Chem. 316 (1991) 143.

[24] Haas, J. Rudnicki, F.R. MacLarnon, E.J. Cairns, J. Chem. Soc., Faraday Trans. 87 (1991) 939.

[25] A. Merle, E. Maurin, J.P. Morand, J. Chem. Phys. 86 (1989) 173.

[26] C. Barbero, M.C. Miras, E.J. Calvo, R. Kotz, O. Haas, Langmuir 18 (2002) 2756.

[27] C. Barbero, M.C. Miras, R. Kötz, Electrochim. Acta 37 (1992) 429.

[28] E. Vieil, C. Lopez, J. Electroanal. Chem. 466 (1999) 218.

[29] T. Ohsaka, S. Kunimura, N. Oyama, Electrochim. Acta 33 (1988) 639.

[30] A. Guenbour, A. Kacemi, A. Benbachir, L. Aries, Prog. Org. Coat. $38(2000) 121$.

[31] C. Barbero, J.J. Silber, L. Sereno, J. Electroanal. Chem. 263 (1989) 333

[32] S. Kunimura, T. Osaka, N. Oyama, Macromolecules 21 (1988) 894.

[33] H. Ju, Y. Xiao, X. Lu, H. Chen, J. Electroanal. Chem. 518 (2002) 123.

[34] G. Socrates, Infrared and Raman Characteristic Group Frequencies, Wiley, Chichester, 2001.

[35] S. Quillard, K. Berrada, G. Louarn, S. Lefrant, M. Lapkowski, A. Pron, New J. Chem. 19 (1995) 365.

[36] T. Lindfors, C. Kvarnström, A. Ivaska, J. Electroanal. Chem. 518 (2002) 131

[37] S. Stafstrom, J.L. Bredas, A.J. Epstein, H.S. Woo, D.B. Tanner, W.S. Huang, A.G. MacDiarmid, Phys. Rev. Lett. 59 (1987) 1464

[38] G.E. Asturias, A.G. MacDiarmid, R.P. McCall, A.J. Epstein, Synth. Met. 29 (1989) E157.

[39] J.G. Masters, Y. Sun, A.G. MacDiarmid, A.J. Epstein, Synth. Met. 715 (1991) 41.

[40] D. Lin-Vien, N.B. Colthup, W.G. Fateley, J.G. Grasselli, Handbook of Infrared and Raman Characteristic Frequencies of Organic Molecules, Academic Press, London, 1991.

A. Zimmerman, U. Kiinzelmann, L. Dünsch, Synth. Met. 93513 (1998) 17.

[42] J.D. Rudnicki, G.M. Brisard, H.A. Gasteiger, R.E. Russo, F.R. 515 McLarnon, E.J. Cairns, J. Electroanal. Chem. 362 (1993) 55. 